\title{
Advantages of technetium pyrophosphate scintigraphy over plasma enzyme analysis in estimation of anterior myocardial infarct size
}

\author{
S SALTISSI, P S ROBINSON, M M WEBB-PEPLOE, \\ D J COLTART, D N CROFT \\ From the Departments of Nuclear Medicine and Cardiology, St Thomas' Hospital, London
}

SUMMARY Infarct size was estimated by cumulative creatine kinase MB isoenzyme (CKMB-r) release and by technetium $99 \mathrm{~m}$ stannous pyrophosphate (TcPYP) scintigraphy in 27 patients with acute anterior myocardial infarction.

In eight patients, scintigraphy showed a central area of reduced tracer uptake surrounded by a peripheral rim of increased TcPYP accumulation ("doughnut" pattern). This appearance occurred only in large infarcts and the maximal scintigraphic area $\left(51.3 \pm 2.8 \mathrm{~cm}^{2}\right.$, mean $\left.\pm S E M\right)$ in this group was significantly greater than that in the remainder $\left(28.1 \pm 2.5 \mathrm{~cm}^{2}\right)$. Correlation between CKMB-r and maximal scintigraphic infarct area was moderate in the whole group. Exclusion of patients, however, with "doughnut" scintigrams in which correlation was very poor, resulted in substantial improvement in the remainder.

It is suggested that in the central regions of large "doughnut" infarcts, reduced blood flow hinders the efflux of CKMB from the centre causing an underestimate of infarct size. Pyrophosphate scintigraphy appears to be more accurate than CKMB release in measuring the size of these large anterior infarcts.

In recent years, awareness of the prognostic importance of the extent of myocardial necrosis ${ }^{2}$ and the postulated existence of an ischaemic but potentially viable border $z^{3} e^{34}$ have led to attempts to reduce infarct size. ${ }^{5-7}$ Assessment of the efficacy of such therapeutic intervention in man requires accurate and reliable methods of measuring infarct size which may be applied in the early postinfarct period.

Many different approaches have been tried, ${ }^{8}$ including analysis of plasma enzyme time-activity curves, ${ }^{9-11}$ technetium $99 \mathrm{~m}$ pyrophosphate (TcPYP) scintigraphy, ${ }^{12} 13$ and praecordial electrocardiographic mapping. ${ }^{14}$ All are open to criticism but creatine kinase (CK) analysis has been regarded as the most accurate and has become accepted as a reference technique. Recently, however, very poor correlation has been reported between CK-derived estimates of myocardial necrosis" and histological infarct size after experimental infarction in dogs..$^{15} 16$ The major factor responsible for this poor correlation was impaired enzyme release into plasma from large infarcts. In the present study we assess whether this is so in patients with myocardial infarcts.

Received for publication 16 June 1980

\section{Subjects and methods}

The study involved 27 patients who fulfilled all the following criteria (a) typical cardiac pain starting started within six hours of admission, (b) 12 lead electrocardiographic changes of anterior myocardial infarction (development of $Q$ waves $\geqslant 0.04 \mathrm{~s}$ duration in one or more of leads I, aVL, V1-6), and (c) a rise in plasma creatine kinase $M B$ isoenzyme (CKMB) with a typical time-course. Patients over 70 years and those in established cardiogenic shock were excluded.

Initially, a clinical history was taken and examination performed. Twelve lead electrocardiography was carried out daily for three days, on day 7 , and before discharge. Blood sampling for the measurement of plasma CKMB was performed four hourly for $\mathbf{2 4}$ hours, six hourly for the next $\mathbf{4 8}$ hours, and eight hourly for a further 24 hours or until two consecutive specimens were enzyme negative. Total creatine kinase $(\mathrm{CK})$ was estimated spectrophotometrically by the method of Oliver ${ }^{17}$ as modified by Hearse $e t$ al. ${ }^{18} \mathrm{CK}$ isoenzymes were separated by thin layer agarose gel electrophoresis and quantified by spectrophotofluorometric analysis of the 
NADPH produced after substrate gel overlay incubation. ${ }^{19}$

A Varian 71 computer was used to generate each plasma CKMB time-activity curve, to fit an exponential to the downslope of the curve using the least squares method (Fig. 1), and to derive an individual disappearance constant ( $k d$ ) of CKMB from plasma for each patient."1 The cumulative release of CKMB (CKMB-r) was calculated using a modification $^{20}$ (Fig. 2) of the original formula of Shell et al. ${ }^{9} \mathrm{CKMB}-\mathrm{r}$ represents the total amount of CKMB which would appear in the plasma in the absence of enzyme disappearance. We have used CKMB-r as an enzymatic index of infarct size in
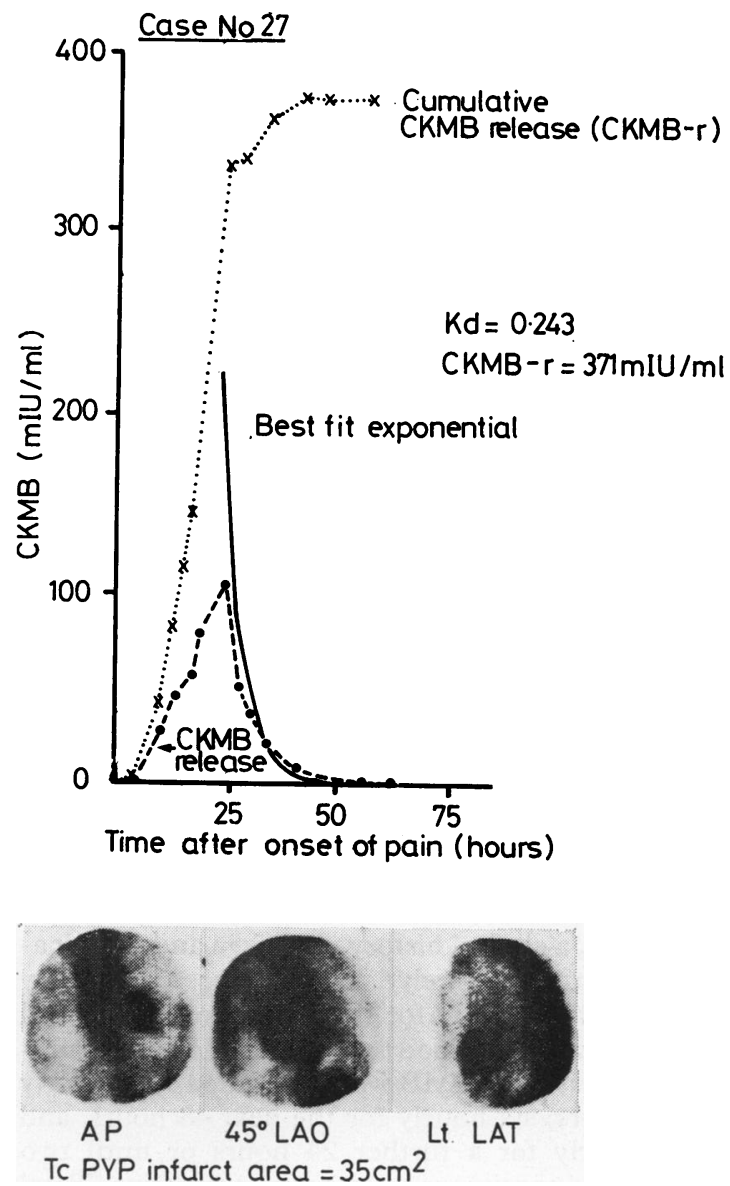

Fig. 1 Enzymatic and scintigraphic infarct size. Above-the computer derived plasma CKMB curves. Below-the TcPYP scintigrams for case 27 showing fairly homogeneous TCPYP uptake in a medium sized anterior infarct (contrast with Fig. 4).

$$
C K M B-r=\int_{0}^{T} f(t) d t=E(T)+K d \int_{0}^{T} E(t) d t
$$

where CKMB-r = cumulative activity of creatine kinase MB isoenzyme (CKMB) released by the heart up to time $T$ hours ( $\mathrm{mlU}$ / $\mathrm{ml}$ ). This represents total enzyme that would appear in plasma if no disappearance occurred.

$f(t)=$ rate of change of plasma CKMB activity due to release of enzyme by the heart $(\mathrm{mlU} / \mathrm{ml}$ per $\mathrm{hr})$.

$E(T)=$ CKMB activity at time $T$ hours (equals zero for the completed curve).

$\mathrm{Kd}=$ individualised disappearance constant for CKMB from plasma/hr.

$E(t)=C K M B$ activity at any time $t$ hours (where $\mathrm{t}<\mathrm{T}$ hours).

NB: An initial CKMB activity, $E(t)$, of zero is assumed and sampling is continued until the final CKMB activity, $E(T)$ equals zero.

Fig. 2 Modification ${ }^{20}$ of the original formula of Shell et al. ${ }^{\circ}$ for the calculation of cumulative CKMB release.

this study. It has the advantage that its derivation depends only on measured plasma CKMB and its rate of disappearance, making no assumptions regarding CKMB distribution volume, amount of CKMB depleted from the heart, or the proportion of depleted CKMB which appears in plasma.

Myocardial infarct scintigraphy was performed on the second to third post-infarct day, approximately two hours after the intravenous administration of $15 \mathrm{mCi}$ of $\mathrm{Tc} 99 \mathrm{~m}$ stannous pyrophosphate. Images were obtained using a portable gamma camera (International General Electric Portakamera II) with a low energy, high resolution parallel hold collimator: 700000 counts were acquired in each of the anterior, left anterior oblique (LAO), and left lateral projections (Fig. 1). The images were processed by a microprocessor (Microtech Electronics Ltd) and displayed on a colour television with a 16 colour scale. Image processing (Fig. 3) consisted of empirical background subtraction (usually 5 to $15 \%$ ) to enhance edge definition, outlining of the region of increased tracer uptake by computerised light bug manipulation, and measurement of the enclosed area. The maximal projected such area in any of the three views of each patient was used as an index of infarct size for comparison with CKMB-r. TcPYP scintigrams were assessed independently by two observers, neither of whom 
had prior knowledge of the results of plasma enzyme analysis. Agreement on the site of TcPYP abnormality occurred in all cases. Interobserver variation in quantifying this area was approximately 10 to 15 per cent and intraobserver variation was approximately 5 per cent.

\section{Results}

Twenty-seven patients (23 men, four women) whose ages ranged from 39 to 69 years (mean $55.2 \pm 1.5$ years; standard exror of the mean, SEM) were studied. Clinical details of these patients are presented in Table 1 . TcPYP scintigraphy showed areas of discrete tracer uptake in all cases, and use of the three projections enabled localisation of infarcts to regions which corresponded anatomically with electrocardiographic infarct sites. The maximal area of increased TcPYP uptake varied widely from 11 to $62 \mathrm{~cm}^{2}$ as shown in Table 1 , and in the majority of cases (16 out of 27 patients) it was observed in the anterior view.

The scintigrams from eight patients showed distribution of activity consisting of a peripheral rim of increased tracer uptake surrounding a central
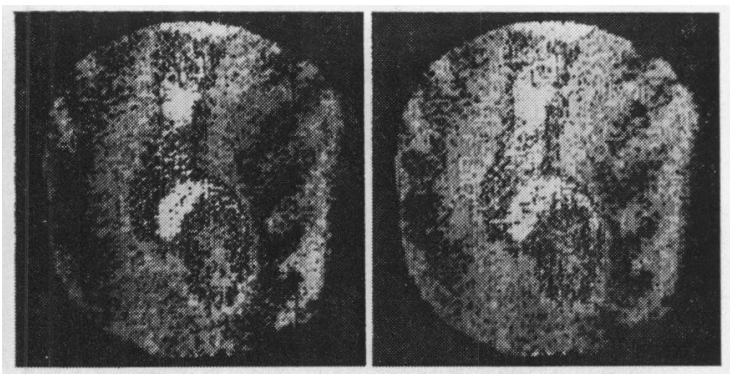

1 Raw image
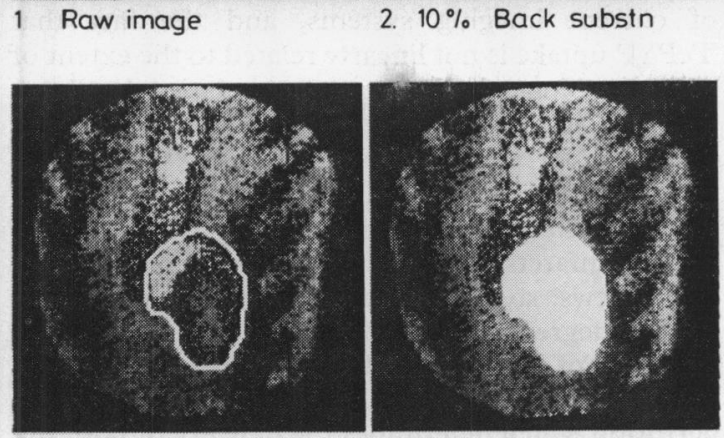

3 Outlined ROI

4 Infilled ROI pixels $=1357$ Tc PYP infarct area $=62 \mathrm{~cm}^{2}$

Fig. 3 Processing of the TcPYP scintigrams. The raw images are background subtracted outlined using a computer lightbug, and then infarct area quantified.
Table 1 Clinical details and TcPYP scintigraphic data

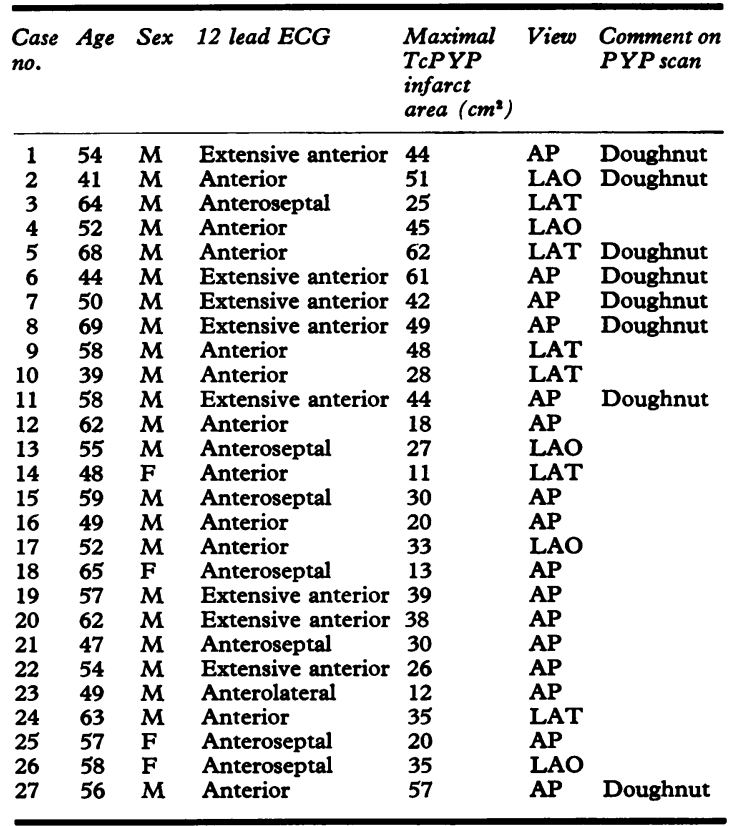

Extensive anterior infarction = pathological " $Q$ " waves in $I$, aVL, and V1-6. Anterior infarction = pathological " $Q$ " waves in V1-5 or V1-6 only. Anteroseptal infarction=pathological " $Q$ " waves in V2-4 only. Anterolateral infarction = pathological " $Q$ " waves in I aVL and V5-6. AP, anteroposterior projection. LAO, left anterior oblique projection. LAT, left lateral projection.

region of reduced activity-a configuration which resembles a doughnut (Fig. 4). In the present study, this "doughnut" pattern was found only with larger infarcts. The maximal infarct area in this group ranged from 42 to $62 \mathrm{~cm}^{2}$ (mean $51.3 \pm 2.8 \mathrm{~cm}^{2}$ ) which was significantly greater $(p<0.001)$ than that of the remainder (11 to $48 \mathrm{~cm}^{2}$; mean $28 \cdot 1 \pm 2 \cdot 5$ $\mathrm{cm}^{2}$ ). In five out of the eight patients with "doughnut" scintigrams the 12 lead electrocardiograph showed changes of extensive anterior myocardial infarction (leads I, aVL, and V1-6) whereas only three out of the remaining 19 patients had similar changes.

Plasma enzyme data and the derived CKMB-r values are presented in Table 2. CKMB-r ranged from 74 to $395 \mathrm{mIU} / \mathrm{ml}$. The mean $( \pm S E M)$ for the eight patients with "doughnut" scintigrams was $236.6 \pm 22.5 \mathrm{mIU} / \mathrm{ml}$ which did not differ significantly $(p>0.5)$ from that of the remaining 19 patients $(212.4 \pm 25.0 \mathrm{mIU} / \mathrm{ml})$.

Overall correlation between TCPYP infarct area and CKMB was moderate $(r=0.60)$ (Fig. 5). In the eight patients with "doughnut" scintigrams, cor- 
relation was poor $(r=0.28)$ and their exclusion produced very good correlation in the remainder $(r=0.86)$ (Fig. 6).

\section{Discussion}

Focal myocardial uptake of TcPYP has been shown to be a sensitive and relatively specific indicator of acute myocardial necrosis. ${ }^{21} 22$ Previous studies in

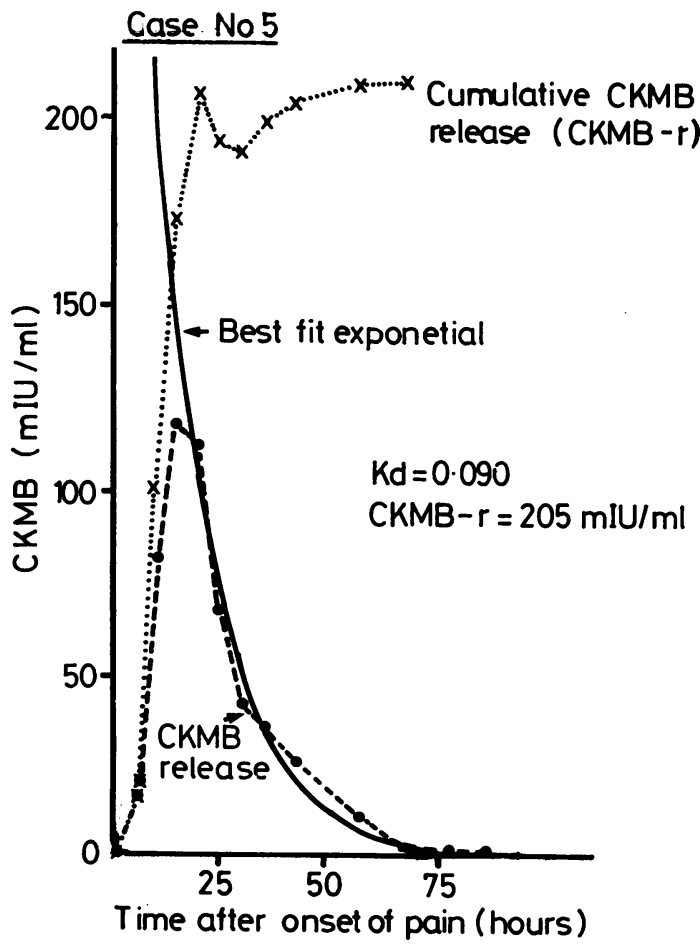

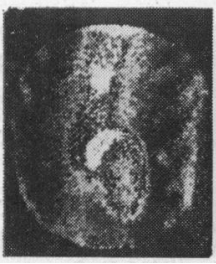

AP

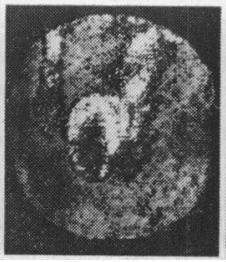

$45^{\circ} \mathrm{LAO}$

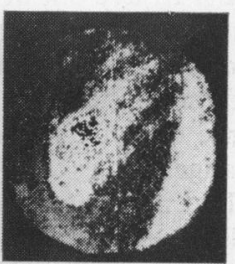

Lt LAT
Tc PYP infarct area $=62 \mathrm{~cm}^{2}$

Fig. 4 Enzymatic and scintigraphic infarct size. Above-the computer derived plasma CKMB curves. Below-the TcPYP scintigrams from case 5 showing a "doughnut" pattern of TcPYP uptake in an extensive anterior infarct (contrast with Fig. 1).
Table 2 Enzymatic data

\begin{tabular}{|c|c|c|c|c|}
\hline $\begin{array}{l}\text { Case } \\
\text { no. }\end{array}$ & $K d / h$ & $\begin{array}{l}\text { Area under release } \\
\text { curve ( } m I U . h \text { per } m l)\end{array}$ & $\begin{array}{l}C K M B-r \\
(m I U / m l)\end{array}$ & $\begin{array}{l}\text { Comment on } \\
P Y P \text { scan }\end{array}$ \\
\hline 1 & -0.153 & 933 & 143 & Doughnut \\
\hline 2 & -0.182 & 1158 & 211 & Doughnut \\
\hline 3 & -0.123 & 1910 & 234 & \\
\hline 4 & -0.236 & 1433 & 338 & \\
\hline 5 & -0.090 & 2279 & 205 & Doughnut \\
\hline 6 & -0.127 & 2052 & 249 & Doughnut \\
\hline 7 & -0.152 & 1610 & 245 & Doughnut \\
\hline 8 & -0.089 & 2350 & 210 & Doughnut \\
\hline 9 & -0.095 & 4148 & 395 & \\
\hline 10 & -0.205 & 1164 & 238 & \\
\hline 11 & -0.109 & 2387 & 259 & Doughnut \\
\hline 12 & -0.151 & 1274 & 192 & \\
\hline 13 & -0.060 & 2295 & 137 & \\
\hline 14 & -0.101 & 738 & 74 & \\
\hline 15 & -0.088 & 2492 & 220 & \\
\hline 16 & -0.040 & 2023 & 80 & \\
\hline 17 & -0.065 & 2138 & 135 & \\
\hline 18 & -0.090 & 1036 & 93 & \\
\hline 19 & -0.117 & 3197 & 373 & \\
\hline 20 & -0.187 & 1374 & 257 & \\
\hline 21 & -0.140 & 1506 & 210 & \\
\hline 22 & -0.140 & 1117 & 156 & \\
\hline 23 & -0.117 & 701 & 82 & \\
\hline 24 & -0.123 & 2772 & 341 & \\
\hline 25 & -0.087 & 1248 & 109 & \\
\hline 26 & -0.243 & 1527 & 371 & \\
\hline 27 & -0.107 & 3405 & 363 & Doughnut \\
\hline
\end{tabular}

$\mathrm{Kd}$, disappearance constant for $\mathrm{CKMB}$ from plasma and is negative to indicate that CKMB levels are decreasing with time.

CKMB-r, cumulative release of CKMB into plasma.

animals ${ }^{23} 24$ have shown excellent correlation between scintigraphic estimates of infarct size and histological infarct area and weight. In man, this relation is complicated by several factors, including gamma photon attenuation of varying degree depending on patient size and infarct location, the age of the infarct at the time of scintigraphy, and the presence of previous infarction. Further problems result from the two-dimensional representation of a three-dimensional structure, the limited resolution of current imaging systems, and the fact that TcPYP uptake is not linearly related to the extent of necrosis. None the less, good correlation has been reported in man between scintigraphic area and both peak $\mathrm{CK}^{25}$ and the integrated $C K$ timeactivity curve. ${ }^{26}$ Correlation is much better in anterior infarcts which are seen en face than in inferior infarcts which tend to be imaged "end-on" in all views, so underestimating true infarct size. ${ }^{26}$

The degree of TcPYP uptake and hence the intensity of the scintigraphic image depends not only on the extent of necrosis but also on the residual perfusion which determines the delivery of both the radiopharmaceutical and of calcium to the infarct. The calcium accumulates in mitochondria usually as apatite-like spicules or deposits of subcrystalline finely granular material ${ }^{27}$ to which the TcPYP is able to complex. Tracer accumulation is maximal 


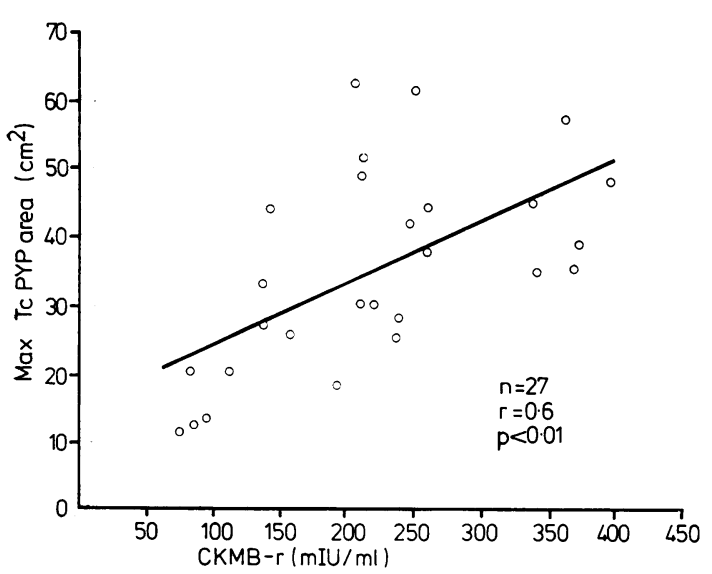

Fig. 5 Correlation between maximal TcPYP infarct area and $C K M B-r$ in all 27 patients with acute anterior myocardial infarction.

at the periphery of the infarct ${ }^{27-29}$ where flow is sufficiently impaired ( 30 to $50 \%$ of normal) to cause cell necrosis but remains adequate for the delivery of calcium and TCPYP. In contrast, at the centre of the infarct, dense necrosis occurs and residual perfusion ( 1 to $10 \%$ of normal) is insufficient to provide adequate delivery of TCPYP and calcium. Such regions consequently have lower concentrations of TcPYP and hence may appear less positive on scintigraphy. ${ }^{27}$ These differences in flow and

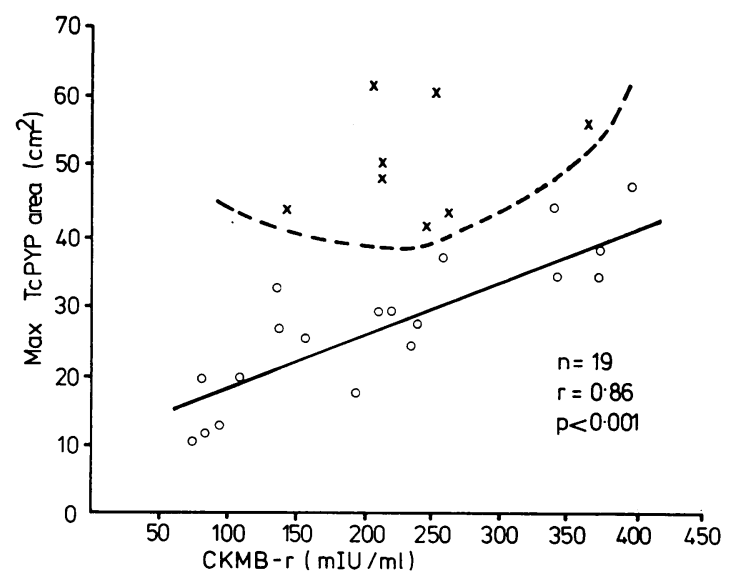

Fig. 6 Correlation between maximal TcPYP infarct area and CKMB-r in 19 patients with homogeneous scintigrams. The subgroup of patients with "doughnut" images (marked with crosses) lies above and to the left of the regression line. tracer accumulation between the centre and periphery of the infarct are maximal in large infarcts and may result in a "doughnut" pattern of tracer distribution (Fig. 4 and 7). This scintigraphic appearance has been observed frequently in dogs ${ }^{30}$ and occasionally in $\operatorname{man}^{13}{ }^{26}$ after extensive anterior infarction.

In the present study, eight patients showed this appearance and in these, scintigraphic infarct area is significantly more extensive $(\mathrm{p}<0.001)$ than in those with homogeneous images. Correlation between scintigraphic and enzymatic estimates of infarct size in this group is poor $(r=0.28)$. Its exclusion results in substantial improvement in correlation $(r=0.86)$, suggesting that the reduction in overall correlation $(r=0.6)$ is primarily because of these patients with

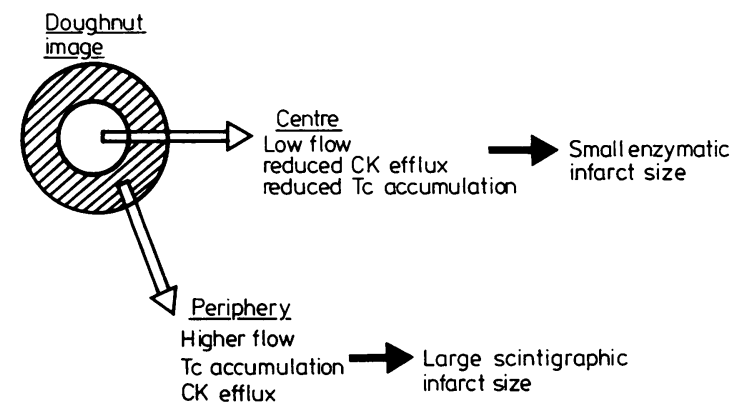

Fig. 7 Summary of the changes which underly the production of the "doughnut" distribution of TcPYP and which lead to poor correlation with enzymatic estimates of infarct size.

large infarcts. Roe et al. ${ }^{15}$ also found that the correlation between histological and enzymatic infarct size in dogs subjected to permanent circumflex artery occlusion, which was initially poor, improved considerably after exclusion of animals with large infarcts.

These patients with "doughnut" scintigrams constitute a distinct subgroup above and to the left of the regression line through the other infarcts (Fig. 6). This implies that either the TcPYP scan overestimates or that CKMB-r underestimates the true infarct size in these patients. Several factors support the latter premise. Firstly there is convincing experimental evidence that TcPYP accumulates almost exclusively in necrotic myocardium and only to a very limited extent in ischaemic, non-necrotic tissue. ${ }^{27} 30$ Thus though some overestimation of infarct size may well occur, it is likely to play a minor role in explaining the poor correla- 
Fig. 8 The effect of alterations in perfusion of an ischaemic region on infarct size estimation from plasma enzyme levels.
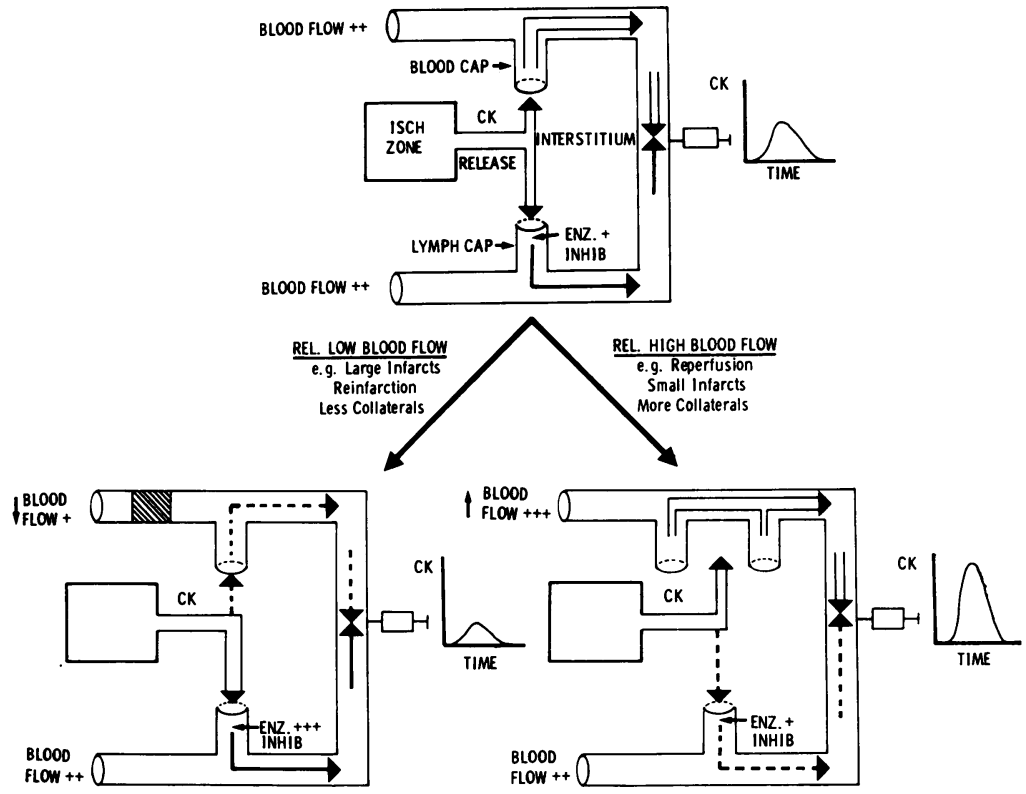

tions observed. Secondly, in seven of the eight patients with "doughnut" scintigrams, CKMB-r indicated only a small or medium sized infarct, whereas standard electrocardiography indicated large anterior infarcts in all and extensive changes involving leads I, aVL, and V1-6 in five. Thirdly, Roe et al. ${ }^{31}$ showed the dependence of enzyme release on perfusion by showing that the appearance rate of enzyme in plasma was related to alterations of infarct blood flow rather than to the extent of infarction and that further reduction of blood flow to an already ischaemic zone resulted in an immediate decrease in the amount of CK being released. ${ }^{32}$ Since perfusion is much reduced in the central regions of large infarcts, the release of CKMB into plasma by the normal channels is impaired. A greater proportion than usual therefore occurs via the lymphatics in which CKMB inactivation is known to occur. ${ }^{33}{ }^{34}$ The resulting plasma enzyme levels are thus reduced and their analysis underestimates infarct size (Fig. 8).

Scintigraphic estimation of infarct size, however, is not affected in the same way by alterations in residual perfusion since it is based on the total area of tracer uptake enclosed within the peripheral rim in which perfusion is maintained at levels favouring TCPYP and calcium accumulation. ${ }^{27-29}$ Consequently, in large infarcts, correlation between enzymatic and scintigraphic estimates of the extent of infarction is poor (Fig. 8). The greater residual blood flow present throughout less extensive areas of necrosis allows unhindered enzyme release which explains the good agreement found in this study and previous ones ${ }^{26}{ }^{35}$ between enzyme analysis and scintigraphy in small and medium sized infarcts.

In small and medium sized anterior infarcts, a reasonably accurate measure is obtained, but in larger ones, infarct size is underestimated because of impaired perfusion and enzyme release. A "doughnut" scintigraphic image indicates that flow disturbances are pronounced and hence that reduction in enzyme release is likely. TcPYP scintigraphy thus provides a valuable means of identifying those infarcts in which plasma CKMB analysis is inaccurate and, despite its inherent limitations, constitutes a more accurate method of measuring infarct size in such patients.

We thank Drs R Bradley and B S Jenkins for allowing us to study patients admitted to the Intensive Care Unit, St Thomas' Hospital.

\section{References}

1 Page DL, Caulfield JB, Kastor JA, DeSanctis RW, Sanders CA. Myocardial changes associated with cardiogenic shock. N Engl f Med 1971; 285: 133-7.

2 Caulfield JB, Leinbach R, Gold $\mathrm{H}$. The relationship of myocardial infarct size and prognosis. Circulation 1976; 53, suppl. 1: 141-4.

3 Cox JL, McLaughlin VW, Flowers NC, Horan LG. The ischemic zone surrounding acute myocardial 
infarction. Its morphology as detected by dehydrogenase staining. Am Heart $\mathcal{f} 1968$; 76: 650-9.

4 Hearse DJ, Opie LH, Katzeff IE, et al. Characterization of the "border zone" in acute regional ischemia in the dog. Am $\mathcal{F}$ Cardiol 1977; 40: 716-26.

5 Maroko PR, Braunwald E. Modification of myocardial infarction size after coronary occlusion. Ann Intern Med 1973; 79: 720-33.

6 Norris RM, Clarke ED, Sammel NL, Smith WM, Williams B. Protective effect of propranolol in threatened myocardial infarction. Lancet 1978; ii: 907-9.

7 Maroko PR, Hillis LD, Muller JE, et al. Favourable effects of hyaluronidase on electrocardiographic evidence of necrosis in patients with acute myocardial infarction. $N$ Engl f Med 1977; 296: 898-903.

8 Saltissi S, Robinson PS, Coltart DJ. Estimation of infarct size during life. Proc $R$ Soc (In press).

9 Shell WE, Kjekshus JK, Sobel BE. Quantitative assessment of the extent of myocardial infarction in the conscious dog by means of analysis of serial changes in serum creatine phosphokinase activity. f Clin Invest 1971; 50: 2614-25.

10 Witteveen SAGJ, Hemker HC, Hollaar L, Hermens WT. Quantitation of infarct size in man by means of plasma enzyme levels. Br Heart f 1975; 37: 795-803.

11 Norris RM, Whitlock RML, Barratt-Boyes C, Small $\mathrm{CW}$. Clinical measurement of myocardial infarct size. Modification of a method for the estimation of total creatine phosphokinase release after myocardial infarction. Circulation 1975; 51: 614-20.

12 Willerson JT, Parkey RW Stokely EM., et al. Infarct sizing with Technetium-99m stannous pyrophosphate scintigraphy in dogs and man; relationship between scintigraphic and praecordial mapping estimates of infarct size in patients. Cardiovasc Res 1977; 11: 291-8.

13 Sharpe DN, Botvinick EH, Shames DM, Norman A, Chatterjee K, Parmley WW. The clinical estimation of acute myocardial infarct size with $99 \mathrm{~m}$ Technetium pyrophosphate scintigraphy. Circulation 1978; 57: 307-13.

14 Maroko PR, Libby P, Covell JW, Sobel BE, Ross J Jr, Braunwald E. Praecordial S-T segment elevation mapping: an atraumatic method for assessing alterations in the extent of myocardial ischaemic injury. Am $\mathcal{f}$ Cardiol 1972; 29: 223-30.

15 Roe CR, Cobb FR, Starmer CF. The relationship between enzymatic and histologic estimates of the extent of myocardial infarction in conscious dogs with permanent coronary occlusion. Circulation 1977; 55: 438-49.

16 Swain JL, Cobb FR, Roe CR. Relationship between CK estimates and histologic extent of myocardial infarction and regional blood flow in awake dogs (abstract). Clin Res 1978; 26: 46a.

17 Oliver IT. A spectrophotometric method for the determination of creatine phosphokinase and myokinase. Biochem f 1955; 61: 116-22.

18 Hearse DJ, Humphrey SM, Chain EB. Abrupt reoxygenation of the anoxic potassium-arrested perfused rat heart: a study of myocardial enzyme release. $\mathcal{F ~ M o l ~ C e l l ~ C a r d i o l ~ 1 9 7 3 ; ~ 5 : ~ 3 9 5 - 4 0 7 . ~}$

19 Ogunro EA, Hearse DJ, Shillingford JP. Creatine kinase isoenzymes: their separation and quantitation. Cardiovasc Res 1977; 11: 94-102.

20 Sobel BE, Kjekshus JK, Roberts R. Enzymatic estimation of infarct size. In: Hearse DJ, DeLeiris J, eds. Enzymes in cardiology: diagnosis and research. Chichester: John Wiley, 1979: 257-89.

21 Willerson JT, Parkey RW, Bonte FJ, Meyer SL, Atkins JM, Stokely EM. Technetium stannous pyrophosphate myocardial scintigrams in patients with chest pain of varying etiology. Circulation 1975; 51: 1046-52.

22 Bruno FP, Cobb FR, Rivas F, Goodrich JK. Evaluation of $99 \mathrm{~m}$ Technetium stannous pyrophosphate as an imaging agent in acute myocardial infarction. Circulation 1976; 54: 71-8.

23 Botvinick EH, Shames D, Lappin H, Tyberg JV, Townsend R, Parmley WW. Noninvasive quantitation of myocardial infarction with Technetium $99 \mathrm{~m}$ pyrophosphate. Circulation 1975; 52: 909-15.

24 Stokely EM, Buja LM, Lewis SE, et al. Measurement of acute myocardial infarcts in dogs with $99 \mathrm{~m}$ Tc-stannous pyrophosphate scintigrams. $f \mathrm{Nucl}$ Med 1976; 17: 1-5.

25 Holman BL, Lesch M, Zweiman FG, Temte J, Lown B, Gorlin R. Detection and sizing of acute myocardial infarcts with $99 \mathrm{~m}$ Tc $(\mathrm{Sn})$ tetracycline. $N$ Engl f Med 1974; 291 : 259-63.

26 Henning H, Schelbert H, Righetti A, O'Rourke R, Ashburn W. Tc-99m-pyrophosphate imaging for sizing acute myocardial infarction (abstract). Clin Res 1977; 25: 91a.

27 Buja LM, Parkey RW, Stokely EM, Bonte FJ, Willerson JT. Pathophysiology of Technetium-99m stannous pyrophosphate and Thallium-201 scintigraphy of acute anterior myocardial infarcts in dogs. $\mathcal{f}$ Clin Invest 1976; 57: 1508-22.

28 Beller GA, Khaw BA, Haber E, Smith TW. Localization of radiolabeled cardiac myosin-specific antibody in myocardial infarcts. Circulation 1977; 55 : 74-8.

29 Zaret BL, DiCola VC, Donabedian RK, et al. Dual radionuclide study of myocardial infarction: relationships between myocardial uptake of potassium43. Technetium-99m stannous pyrophosphate, regional myocardial blood flow and creatine phosphokinase depletion. Circulation 1976; 53: 422-8.

30 Buja LM, Parkey RW, Dees JH, et al. Morphologic correlates of Technetium-99m stannous pyrophosphate imaging of acute myocardial infarcts in dogs. Circulation 1975; 52: 596-607.

31 Roe CR, Cobb FR, Starmer CF. Peripheral enzyme appearance rates following acute myocardial infarction (MI): an index of perfusion of infarcted regions (abstract). Circulation 1975; 51 \& 52: suppl II-5.

32 Cobb FR, Irvin RG, Hagerty RC, Roe CC. Effect of extension of infarction on serial CK activity. Circulation 1979; 60: 145-54.

33 Robison AK, Gnepp DR, Sobel BE. Inactivation of CPK in lymph (abstract). Circulation 1975; 51 \& 52: suppl. II-5. 
34 Spieckermann PG, Nordbeck H, Preusse CJ. From heart to plasma. In: Hearse DJ, De Leiris J, eds. Enzymes in cardiology: diagnosis and research. Chichester: John Wiley, 1979: 81-95.

35 Willerson JT, Parkey RW, Harris RA Jr, Bonte FJ, Stokely EM, Buja LM. Sizing acute myocardial infarction utilizing technetium stannous pyrophos- phate myocardial scintigrams in dogs and man (abstract). Clin Res 1975; 23: 214a.

Requests for reprints to Dr D J Coltart, Department of Cardiology, St Thomas' Hospital, London SE1 $7 \mathrm{EH}$. 